\title{
Realization of a Photovoltaic Fed Sparse Alternating Current (AC)-Link Inverter
}

\author{
R. Ramaprabha*, G. Ramya, U. Ashwini and A.H. Fathima Humaira \\ Department of Electrical and Electronics Engineering, SSN College of Engineering, Rajiv Gandhi Sala, \\ Kalavakkam-603110, Tamilnadu, India
}

Received 9 September 2015; Accepted 4 January 2016

\begin{abstract}
In this paper, a soft-switched alternating current (AC)-link buck-boost inverter with a reduced number of switches, referred to as a sparse AC-link buck-boost inverter, was designed and implemented for a photovoltaic (PV) interface. Important features of the sparse configuration included a lower number of switches, lower failure rates, compactness, and cost-effectiveness. The link was composed of a low reactive rating series inductor/capacitor pair. Significant merits of the AC-link buck-boost inverter are a zero voltage turn on and a soft turn off of the switches, resulting in minimum voltage stress on the switches and negligible switching losses. In this paper, 10 switches were used instead of 20 switches as are used in existing buck-boost inverter topology. The reduction in the number of switches did not change the principle of operation of the sparse configuration; hence, it remains the same as that of the original configuration. The pulse width modulation (PWM) technique was used for gating the switches. The inverter operation was validated and implemented for PV interface using a microcontroller.
\end{abstract}

Keywords: Sparse inverter, Photovoltaic systems, Zero voltage switching, MATLAB, Microcontroller.

$$
\text { تحقيق التفذية الكهروضوئة عن طريق الريط بمعاطس متفرق للتيار المتردد }
$$

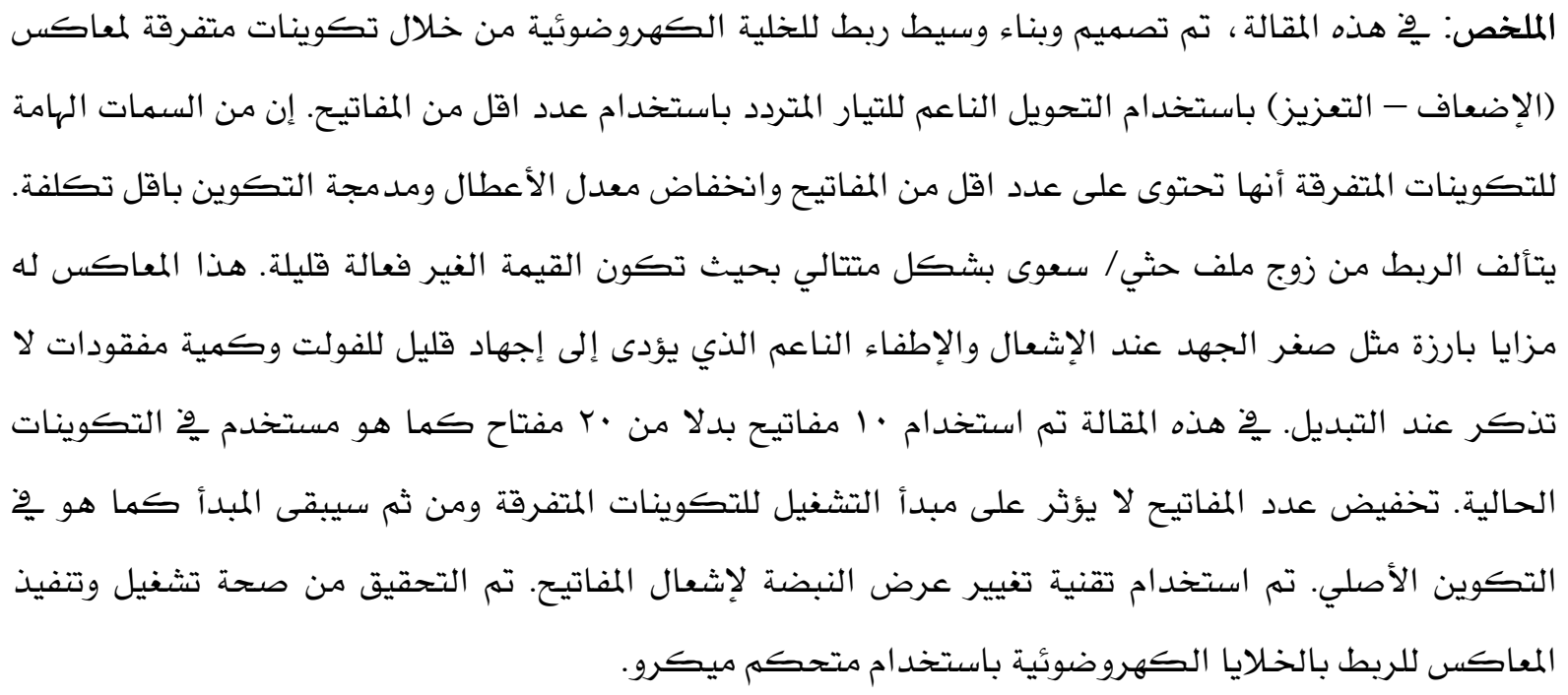




\section{Introduction}

Renewable energy is defined as energy from a source that is not depleted when used (Carlson, 1989), and photovoltaic (PV) energy is the most important renewable energy source available. (Shen 2008). PV systems are the fastest growing energy source worldwide because of an increase in energy demand, and the fact that fossil energy sources are finite and expensive. PV energy is renewable, inexhaustible, and nonpolluting, and can be used for various applications (Zahedi 2002). Unlike other nonrenewable energy sources, solar energy sources produce few or no waste products such as carbon dioxide and other harmful chemical substances (Subudhi and Pradhan 2013).

The major challenge in PV conversion is to use the proper power converter circuits in order to convert produced direct current (DC) to practical DC-alternating current (AC) (Chakraborty et al. 2009). In a standalone or grid-connected system, the conversion of DC to $\mathrm{AC}$ with the proper power quality is important (Atcitty et al. 2011). A number of PV inverter topologies have been presented in the literature (Kerekes et al. 2011). The major challenges are a reduction of switches to reduce losses and the generation of nearly sinusoidal voltage with reduced total harmonic distortion (Kjaer et al. 2005). These converters, which can be configured in many ways, including DC-DC, $\mathrm{DC}-\mathrm{AC}, \mathrm{AC}-\mathrm{DC}$, and $\mathrm{AC}-\mathrm{AC}$ and have many advantages over other types of converters. Specifically, these converters are more compact and reliable, and offer longer lift-time (Qin et al. 2002). However, one complication is that these converters employ more switches than any other power processors (Sood et al. 1988). Their remarkable merits have paved the way for a soft-switching AC-link universal power converter which has received noticeable attention during the last few years (Amirabadi et al. 2009).

In spite of advantages over the AC-link buckboost inverter, a soft-switching AC-link universal power converter requires many switches when compared to a more conventional inverter (Amirabadi 2013); hence, the control method is complicated. In a conventional AC-link buck-boost inverter, the complementary switches are added to provide the pathway for an AC-link current
(Balakrishnan et al. 2008). This AC-link current may reduce the system efficiency with an increased harmonic content. Due to this potential issue, the sparse AC-link inverter is considered, and the configuration with the reduced number of switches is called a sparse AC-link buck-boost inverter. The operating principle of a sparse AC-link inverter is similar to that of a conventional one. The proposed inverter has high reliability and low switching loss (Toliyat et al. 2008). The most important feature of a sparse inverter is that it has unidirectional switches which can be fabricated by switch modules. The sparse configuration is considered to be less expensive, less complicated, and more compact compared to the AC-link buck-boost inverter (Amirabadi 2013). The sparse AC-link inverter supports bidirectional power flow. In this inverter, the complimentary switches are not essential, although they provide AC (Amirabadi 2014). The converter transfer power through the DClink inductor is charged in the input phase and discharged at the output phase. The link frequency is greater than the output line frequency. During the resonance mode, no switches conduct, initiating the soft switching principle (Amirabadi et al. 2009). However, due to the number of switches in the sparse AC-link inverter, the switching loss can be increased, affecting the system's efficiency. Hence, in this paper, the sparse AC-link inverter is proposed with a reduced number of switches. Due to the reduced number of switches, the control method is very simple compared to a conventional AC-link inverter. In the proposed method, a reduced number of switches is used which makes the control process easier. A softswitching AC-link buck-boost inverter traditionally uses 20 switches, but the sparse configuration proposed by Amirabadi et al. (2014) used 18 switches instead of 20.

In this paper, a sparse configuration with 10 switches was implemented for PV interface. The operation was checked with MATLAB/SIMULINK software (MathWorks, Natick, Massachusetts, USA) and validated through practical implementation. The paper is organized as follows: Section 2 describes the design and operation of sparse configuration. Section 3 presents the simulation results, and section 4 presents the hardware implementation. The conclusion is presented in section 5 . 


\section{Design and Operation of PV Connected Sparse AC-link Inverter}

The basic circuit configuration of PV connected sparse AC link inverter is shown in Fig 1. The input side and the output side are formed by four unidirectional switches and six bidirectional switches respectively. This inverter is most similar to a DC-AC buck-boost converter in which the link is charged through PV array and discharged into the output phases.

The charging and discharging of the link in reverse is facilitated by the complementary switches in each leg. This style of discharging leads to an AC in the link, which leads to better utilization of the link inductor and capacitor.

A single-phase high-frequency transformer can be added to the link if isolation is required. The PV panel was modelled using a one-diode model which consists of a current source in parallel with a diode (Villava et al. 2009), a shunt resistance, and a series resistance (Fig. 2). Key modelling is shown in Eqns. 1-4.
In this case, the link inductance of the transformer is playing the role of magnetizing inductance (Amirabadi et al. 2014).

$$
\begin{aligned}
& \mathrm{I}_{\mathrm{O}}=\frac{\mathrm{I}_{\mathrm{Scn}}+\mathrm{K}_{\mathrm{i}} \mathrm{dT}}{\exp \left[\frac{\mathrm{V}_{\mathrm{Ocn}}+\mathrm{K}_{\mathrm{V}} \mathrm{dT}}{\mathrm{V}_{\mathrm{ta}}}\right]-1} \\
& \mathrm{I}_{\mathrm{pv}}=\left[\mathrm{K}_{\mathrm{i}} \mathrm{dT}+\mathrm{I}_{\mathrm{pvn}}\right] \frac{\mathrm{G}}{\mathrm{G} \mathrm{n}} \\
& \mathrm{V}_{\mathrm{ta}}=\frac{\mathrm{N}_{\mathrm{S}} \mathrm{aKT}}{\mathrm{q}} \\
& \mathrm{I}_{\mathrm{m}}=\mathrm{I}_{\mathrm{pv}} \mathrm{N}_{\mathrm{pp}}-\mathrm{I}_{\mathrm{o}} \mathrm{N}_{\mathrm{pp}} \\
& \exp \left[\frac{\mathrm{V}_{\mathrm{ta}}}{\mathrm{N}_{\mathrm{s}}} \times\left(\mathrm{R}_{\mathrm{s}} \frac{\mathrm{N}_{\mathrm{ss}}}{\mathrm{N}_{\mathrm{pp}}} \mathrm{I}+\mathrm{V}\right)-1\right]
\end{aligned}
$$

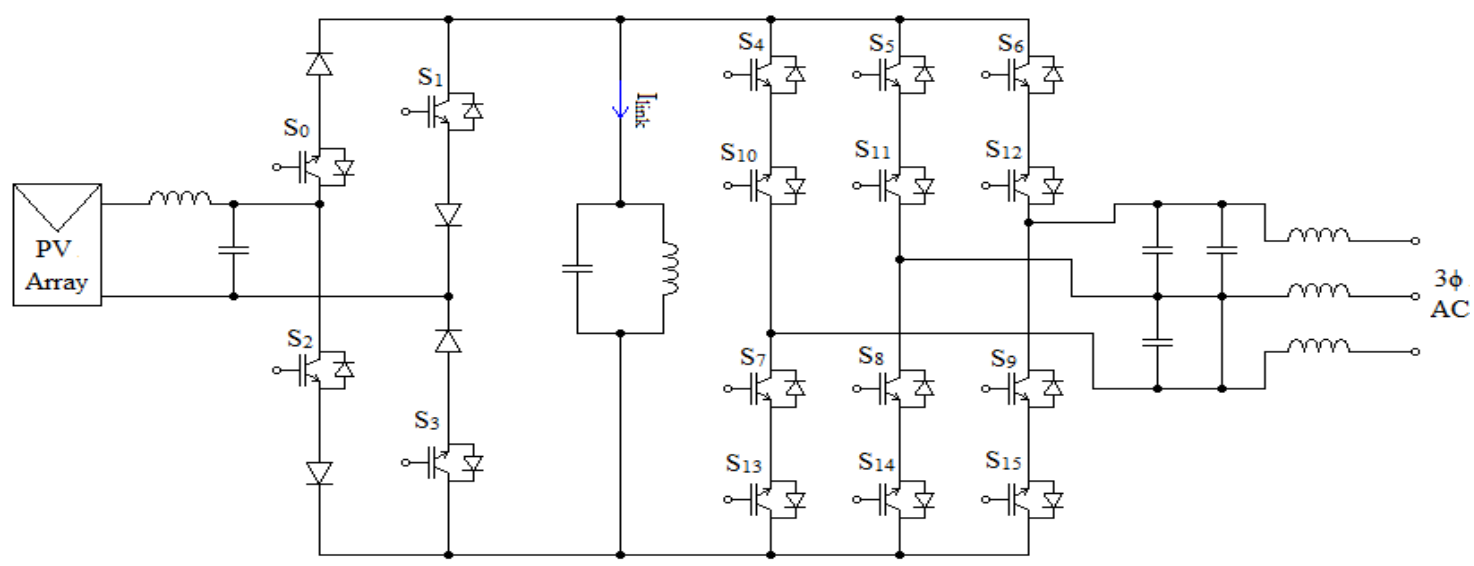

Figure 1. Photovoltaic (PV) interfaced sparse alternating current (AC)-link inverter.

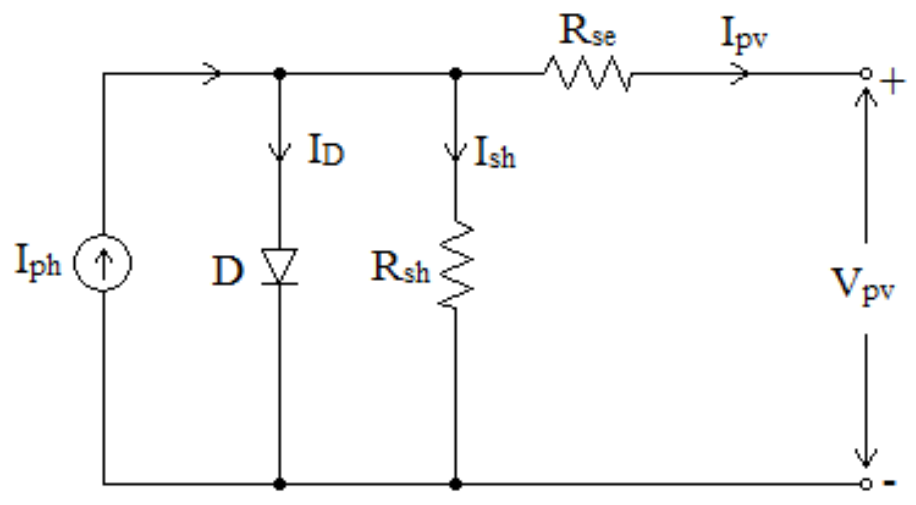

Figure 2. Circuit model used for modelling a photovoltaic (PV) panel. 
The PV array is sized accordingly (considering maximum power point voltage, $\mathrm{V}_{\mathrm{mpp}}$ and current, $\mathrm{I}_{\mathrm{mpp}}$ ) and the system parameters are listed in Table 1.

Table 1. System parameters.

\begin{tabular}{cc}
\hline Parameters & Standards \\
\hline $\mathrm{V}_{\mathrm{mpp}}$ of single panel & $16.54 \mathrm{~V}$ \\
$\mathrm{I}_{\mathrm{mpp}}$ of single panel & $2.55 \mathrm{~A}$ \\
$\mathrm{PV}$ array size/arm & $15 \times 2(15$ panels in \\
& series $)$ \\
\hline
\end{tabular}

The design of an AC link PV inverter is explained below (Amirabadi et al. 2012). For the purpose of simplicity, a resonating time which is less than the power transfer time at full power is neglected. The phase carrying maximum current is involved in de-energizing of the link at modes three and five. The equivalent output voltage and current is given by

$$
\begin{aligned}
& \mathrm{V}_{\text {oeq }}=\frac{\pi \mathrm{V}_{\text {opeak }}}{2} \cos \theta \\
& \mathrm{I}_{\text {oeq }}=\frac{3 \mathrm{I}_{\text {opeak }}}{\pi}
\end{aligned}
$$

where, $\mathrm{I}_{\text {opeak }}$ is the output peak phase current, $\mathrm{V}_{\text {opeak }}$ is the output peak phase voltage, and cos $(\theta)$ is the output power factor. The link current during energizing and de-energizing is given by

$$
\begin{aligned}
& \mathrm{I}_{\text {link, peak }}=\frac{\mathrm{V}_{\mathrm{pv}} \times \mathrm{t}_{\text {charge }}}{\mathrm{L}} \\
& \mathrm{I}_{\text {link, peak }}=\frac{\mathrm{V}_{\text {oeq }} \times \mathrm{t}_{\text {discharge }}}{\mathrm{L}}
\end{aligned}
$$

where, $t_{\text {charge }}$ and $t_{\text {discharge }}$ are the total charging times during mode one and total discharging time during modes three and five.
The average PV current based on the peak of the link current is given as follows:

$$
\mathrm{I}_{\mathrm{pv}}=\frac{1}{\mathrm{~T}}\left(\mathrm{I}_{\text {link, peak }} \times \mathrm{t}_{\text {charge }}\right)
$$

where, $\mathrm{T}$ is the period of the link current. Based on the above equations, the peak link current can be written as:

$$
\mathrm{I}_{\text {link,peak }}=2 \times\left(\mathrm{I}_{\mathrm{pv}}+\mathrm{I}_{\mathrm{oeq}}\right)
$$

The frequency of the link current is determined based on the power rating of the system and the characteristics of available switches. The link inductance is calculated by:

$$
\mathrm{L}=\frac{\mathrm{V}_{\mathrm{pv}}}{\mathrm{I}_{\text {link,peak }}} \frac{1}{2 \mathrm{f}\left(1+\left(\frac{\mathrm{V}_{\mathrm{pv}}}{\mathrm{V}_{\text {oeq }}}\right)\right)}
$$

Link capacitance is calculated such that the resonating periods within $5 \%$ of the link cycle at full power. There are 12 operating modes in 10 switch sparse AC link inverter. The link is energized from the input during modes 1 and 7 and is de-energized to the outputs during modes 3, 5, 9 and 11. Modes 2, 4, 6, 8, 10 and 12 are devoted to resonance. The link current during mode 1 is given by as below:

$\mathrm{V}_{\mathrm{pv}}=\mathrm{L} \frac{\mathrm{di}_{\text {link }}(\mathrm{t})}{\mathrm{dt}}$

$$
\mathrm{i}_{\operatorname{Link}}(\mathrm{t})=\frac{1}{\mathrm{~L}} \int_{0}^{\mathrm{t}} \mathrm{V}_{\mathrm{pv}} \mathrm{dt}=\frac{\mathrm{V}_{\mathrm{pv}} \times \mathrm{t}}{\mathrm{L}}+\mathrm{i}_{\operatorname{Link}}(0)
$$

The operation in different modes is depicted in Table 2. The operating principle is shown in Fig. 3 for each mode (Amirabadi 2013). 

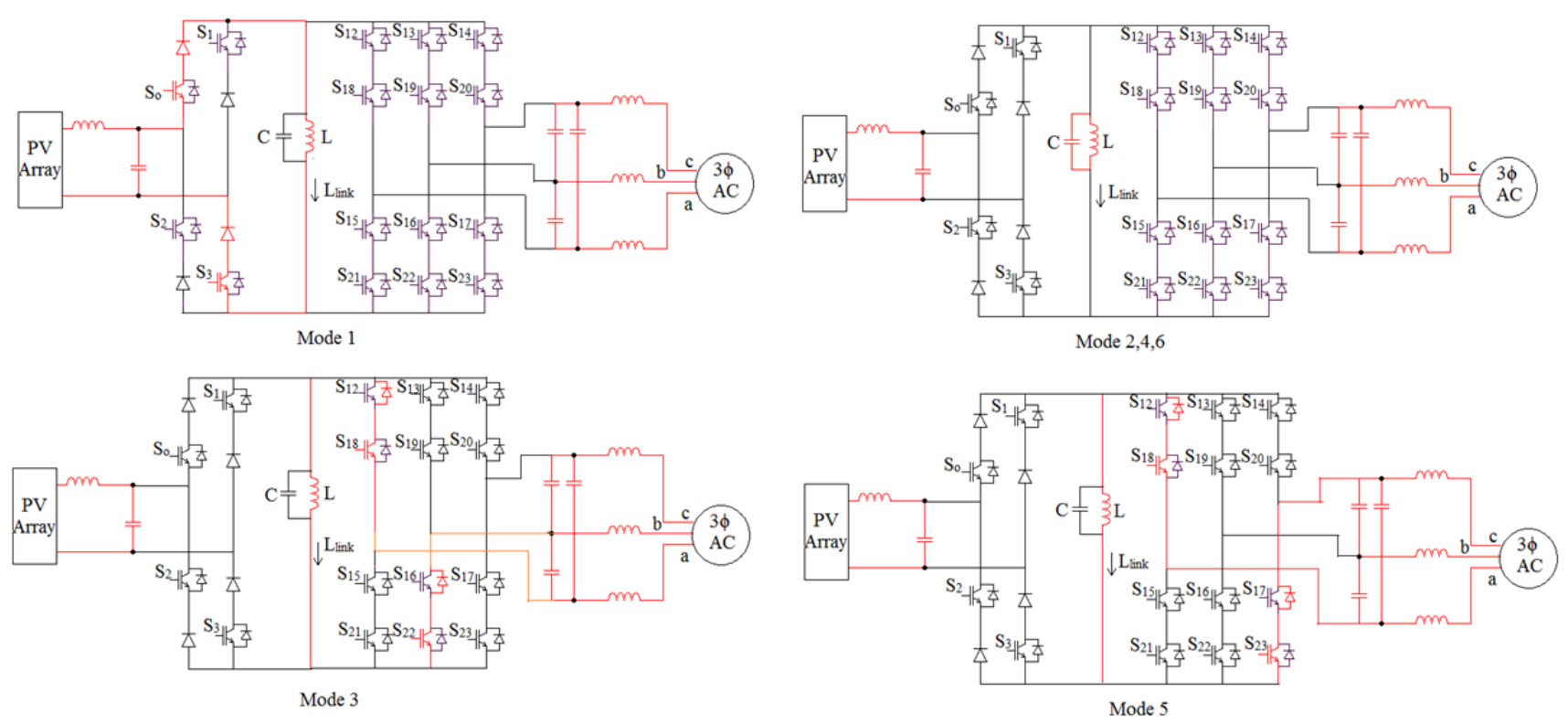

Figure 3. Operating principle of sparse AC link inverter.

Table 2. Modes of operation of 10 switch sparse AC-link inverter.

\begin{tabular}{llll}
\hline Mode & Link operation & $\begin{array}{l}\text { Switches in } \\
\text { ON state }\end{array}$ & $\begin{array}{l}\text { Switches in } \\
\text { conduction }\end{array}$ \\
\hline 1 & Energizing & $\mathrm{S}_{0}$ and $\mathrm{S}_{3}$ & $\mathrm{~S}_{0}$ and $\mathrm{S}_{3}$ \\
2 & Partial Resonance & $\mathrm{S}_{10}, \mathrm{~S}_{14}$ and $\mathrm{S}_{15}$ & None \\
3 & De-energizing & $\mathrm{S}_{10}, \mathrm{~S}_{14}$ and $\mathrm{S}_{15}$ & $\mathrm{~S}_{10}$ and $\mathrm{S}_{14}$ \\
4 & Partial Resonance & $\mathrm{S}_{10}$ and $\mathrm{S}_{15}$ & None \\
5 & De-energizing & $\mathrm{S}_{10}$ and $\mathrm{S}_{15}$ & $\mathrm{~S}_{10}$ and $\mathrm{S}_{15}$ \\
6 & Partial Resonance & $\mathrm{S}_{1}$ and $\mathrm{S}_{2}$ & None \\
\hline \multirow{4}{*}{$7-12$} & $\begin{array}{l}\text { The operations are similar to modes } 1 \text { to } 6 . \text { But the link } \\
\text { charges and discharges in the reverse direction }\end{array}$ \\
& through complimentary switch at each leg. \\
\hline
\end{tabular}

Table 3. Simulation Parameters

\begin{tabular}{ll}
\hline Parameter & Values \\
\hline Nominal PV voltage (DC link) & $240 \mathrm{~V}$ \\
Output voltage & $230 \mathrm{~V}$ \\
Link inductance & $5.5 \mathrm{Mh}$ \\
Link capacitor & $1000 \mathrm{Mf}$ \\
PV side filter & $0.001 \mu \mathrm{H}, 1000 \mu \mathrm{F}$ \\
AC side filter & $0.200 \mu \mathrm{H}, 200 \mu \mathrm{F}$ \\
\hline$P V=$ photovoltaic; $D C=$ direct current; $V=$ volt $; M h=$ megahertz; $M f=$ megaXXX; \\
$A C=$ alternating current; $M h=$ millihenry; $M f=$ millifarad.
\end{tabular}

\section{Simulation Results}

The circuit shown in Fig. 1 was simulated for a $1 \mathrm{~kW}$ PV system using MATLAB/SIMULINK (Fig. 4), and the simulation parameters are presented in Table 3. The filter components were designed using the equations given by Amirabadi et al. (2014). Pulse width modulation (PWM) pulses were generated in proper sequence to turn on the switches. 


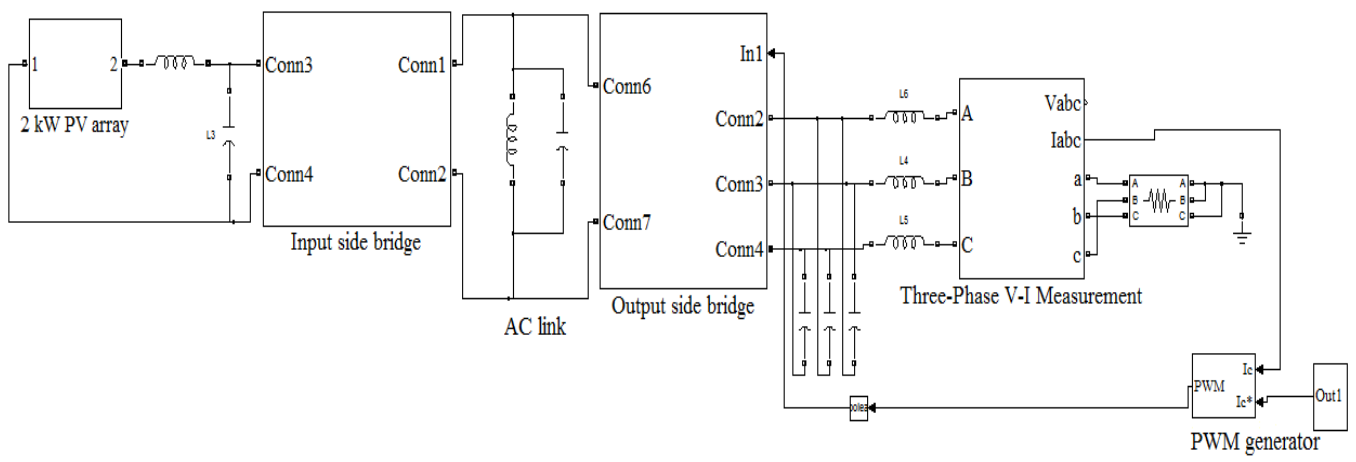

Figure 4. MATLAB model of the 10-switch sparse alternating current (AC)-link inverter.

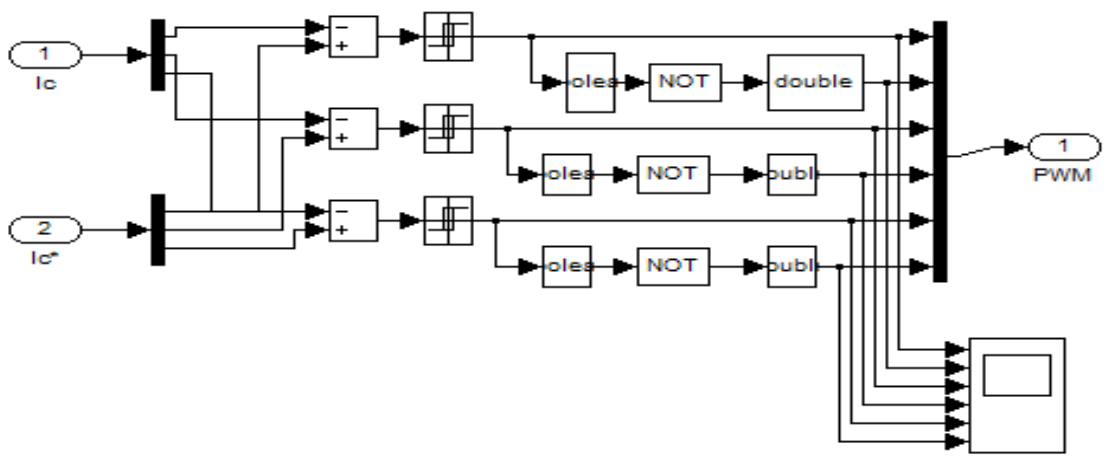

Figure 5. Control circuit for pulse width modulation (PWM) generation.
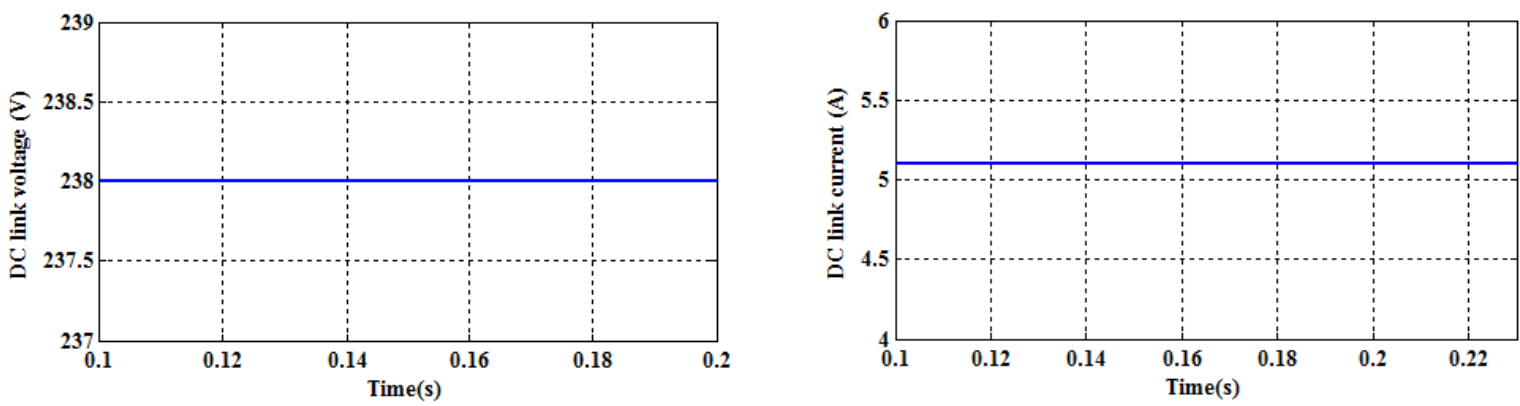

Figure 6. Voltage and current at the direct current (DC) link.

The nominal voltage of $240 \mathrm{~V}$ forming the PV array is given as an input-to-input side bridge, while the output is observed from the three legs of the output side bridge. The input side bridge consists of unidirectional switches while the output side consists of bidirectional switches. The PWM pulses are generated through the control circuit whereas the output current is compared with the reference current (Fig. 5).

The simulation was carried out using MATLAB, and the results are presented below. Figure 6 shows the DC voltage and current from The PV array. The maximum power from the PV array was tracked by the maximum power point tracking algorithm. The maximum power was tracked from the PV array only when the source impedance matched the load impedance.

Figure 7 shows the PWM pulses for switches $\mathrm{S}_{0}-\mathrm{S}_{3}$. The gating sequence to switches $\mathrm{S}_{4}-\mathrm{S}_{15}$ is given by comparing the output current from the inverter (Fig. 8).

Figure 9 shows the input from the DC link voltage and current. In such a set-up, when the capacitor starts charging, the current flowing through the system decreases; when it starts discharging, the current flowing through the system increases. The frequency of the link current is much higher than the frequency of the line. 

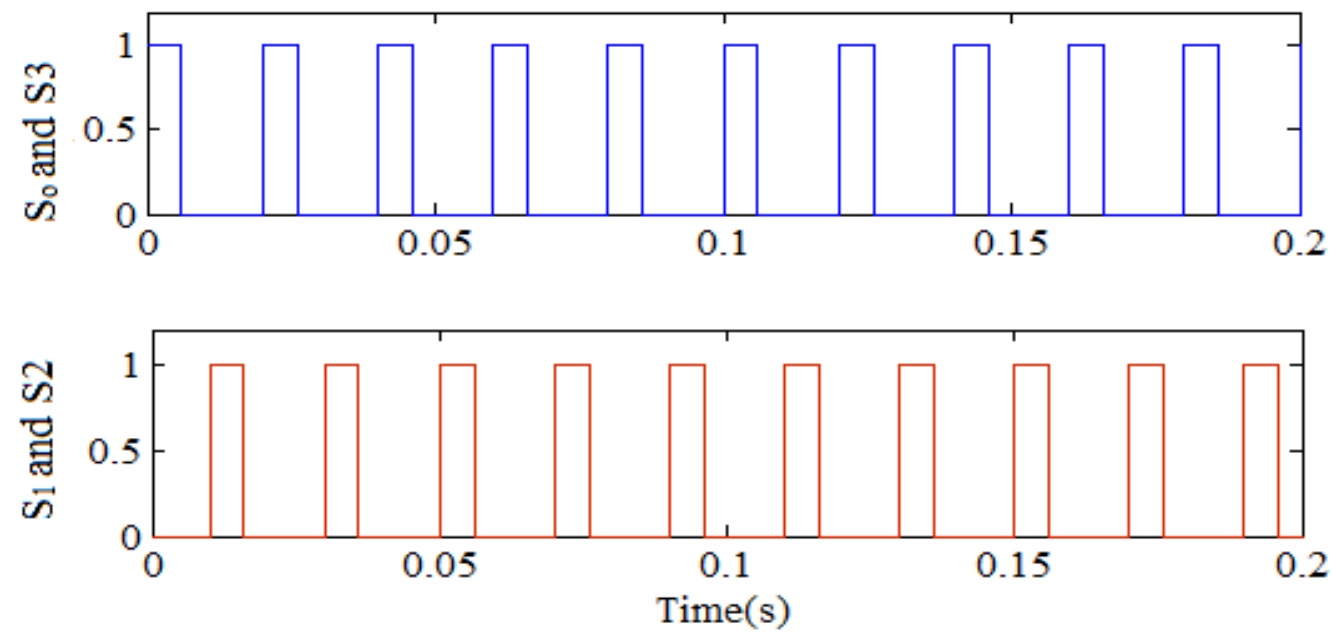

Figure 7. Pulses for the switches in the input side bridge.
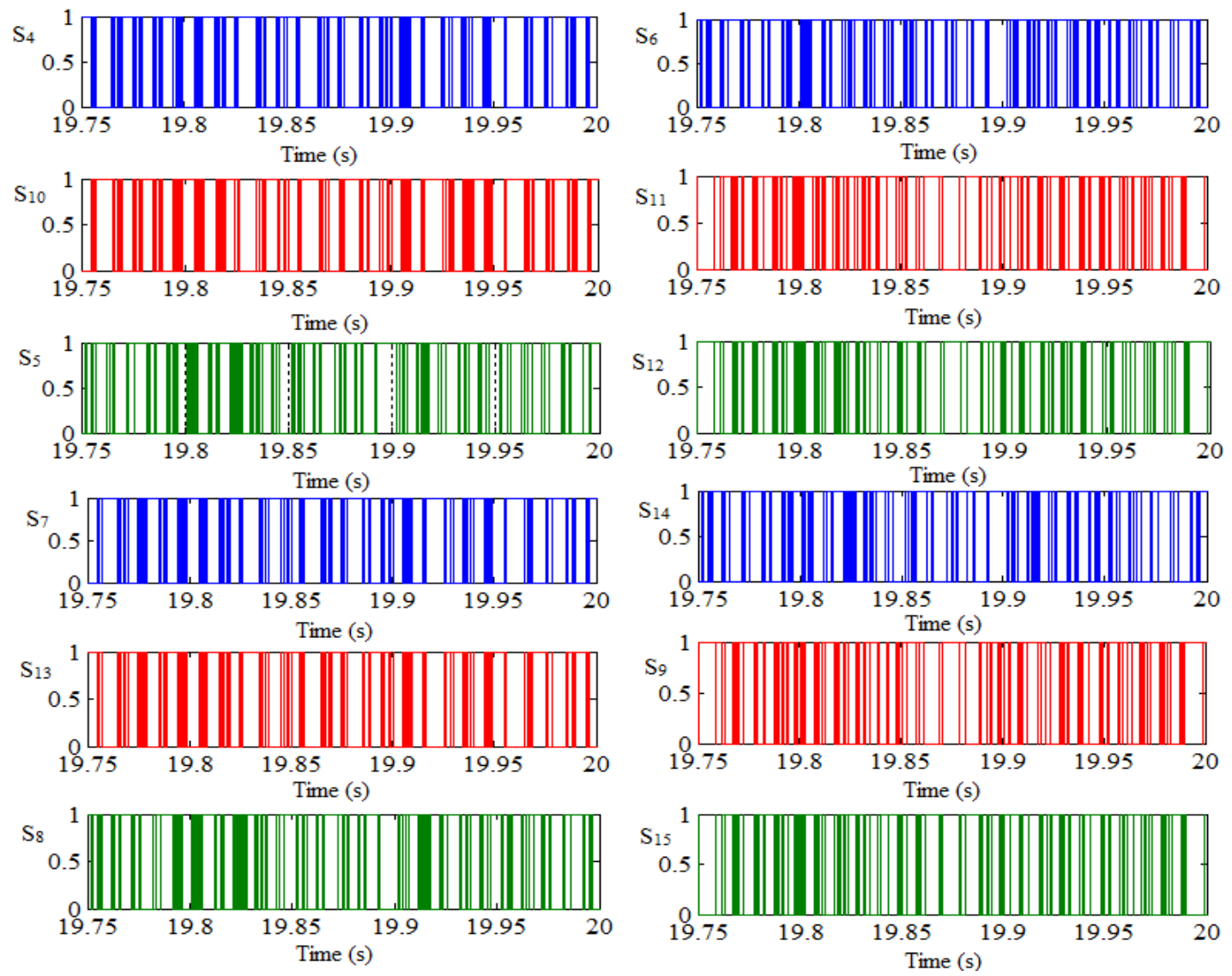

Figure 8. Pulses for the switches in the output side bridge.

Soft switching is carried out in the sparse AC link inverter. Accordingly, there is zero voltage switching when the voltage across the switch is zero. Then the capacitor starts charging. In case of zero current switching, when the voltage across the switch is zero, the current flowing through the inductor is also zero. The soft switching principle is shown in Fig. 10 

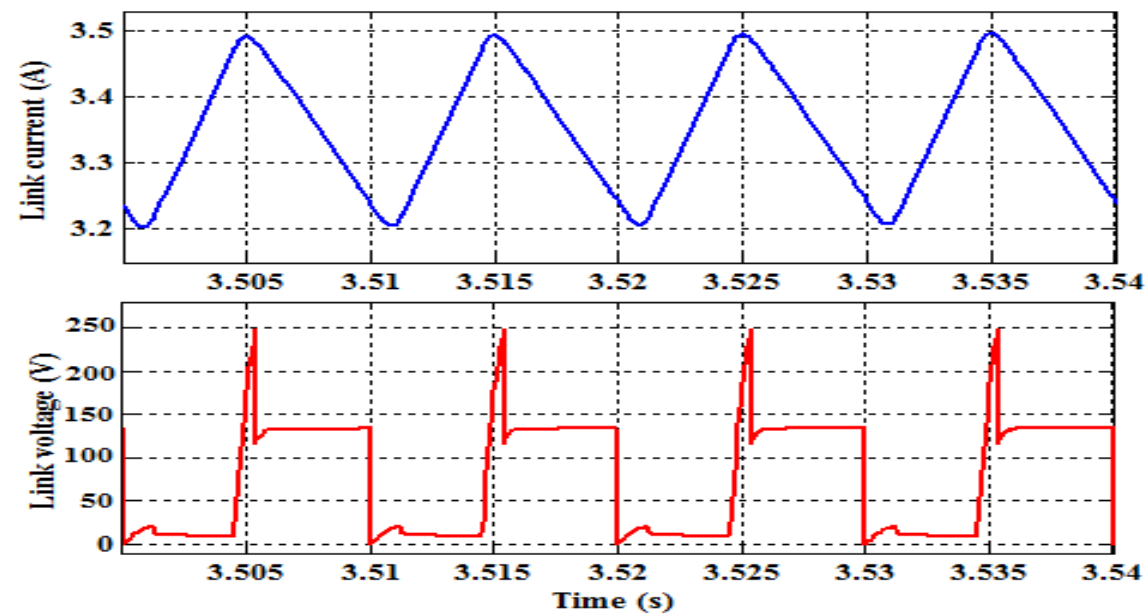

Figure 9. Input dc link current and voltage.
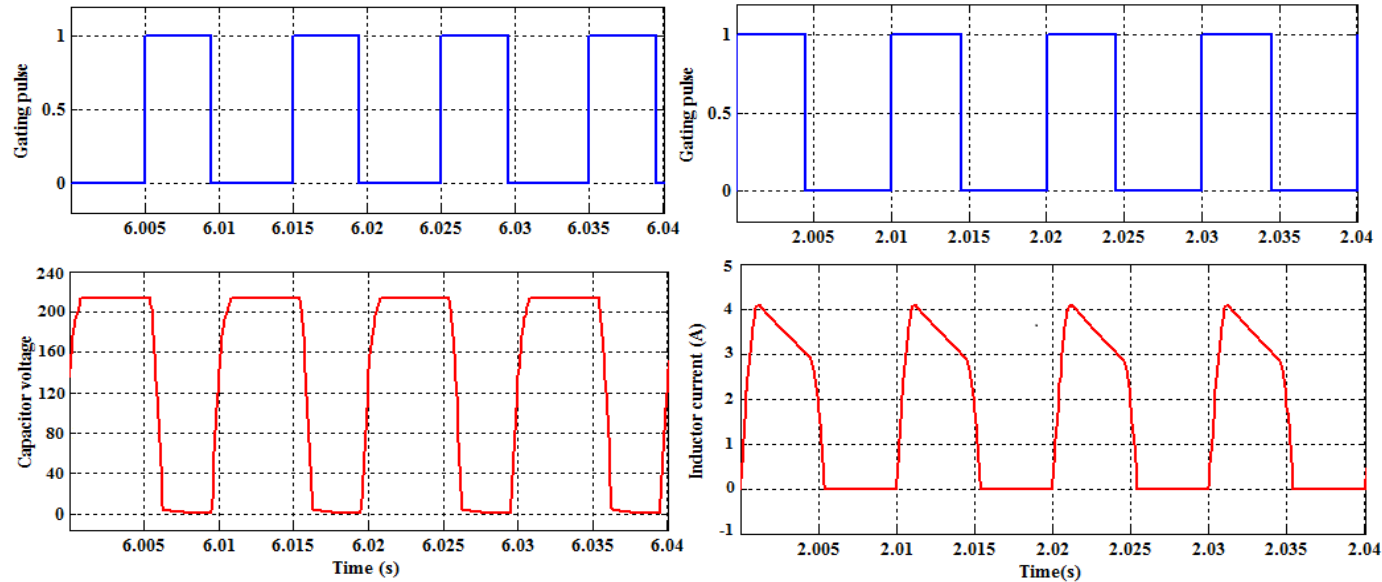

Figure 10. Zero voltage and zero current switching.
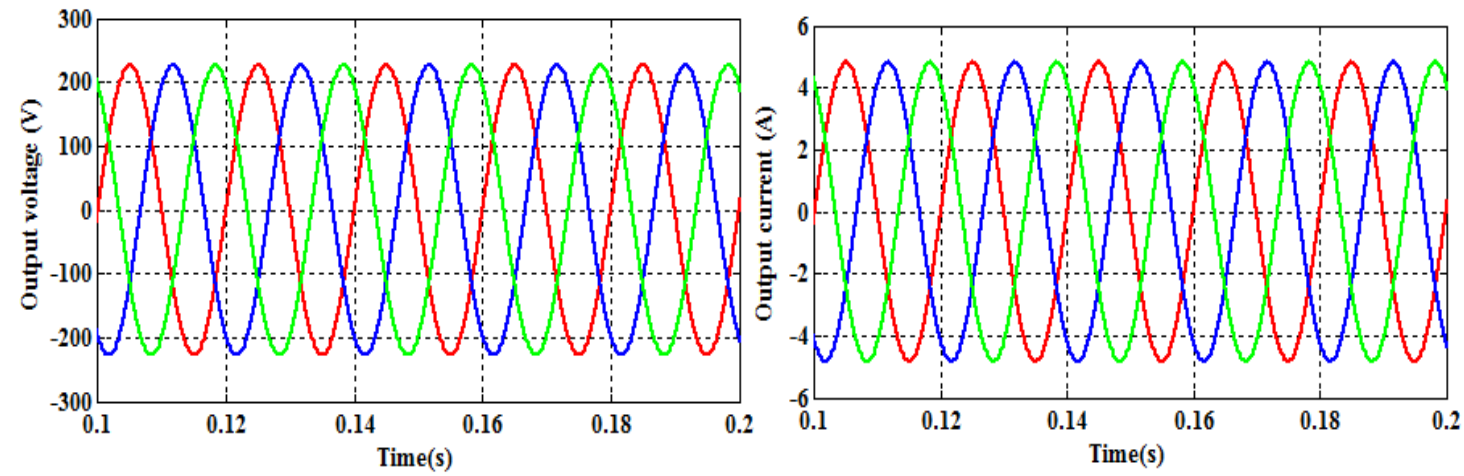

Figure 11. Voltage and current at the alternating current (AC) side.

Figure 11 shows the output voltage and current after filter. The output voltage and current are $3 \phi$ AC. The peak value of the line to line voltage of each phase is $230 \mathrm{~V}$. The peak value of output current is 5 A.
The output voltage is nearly sinusoidal but has a few ripples. The output voltage and current are lower than the input voltage and current. Hence, the output power is lower than the input power, which accounts for the losses. 


\section{Hardware Implementation}

The experimental setup of the sparse AC link inverter is shown in Fig. 12. The gating pulses were created using a field programmable gate array (FPGA) board. The generated pulses are given to the switches of the multi mini capacitor (MMC) via the MCT2E opto-coupler. The power supply circuit for the optocoupler and processor was designed using a step-down transformer, bridge rectifier, and regulator.
A link inductor and link capacitor are present between the input and output sides to perform partial resonance and to provide galvanic isolation. In order to protect the microcontroller and the control circuit from power circuit an isolation circuit is provided. The experimental results are observed using digital storage oscilloscope (DSO). Figure 13 shows the DC link output voltage and current. The three-phase output voltage and current waveform from the inverter is shown in Fig. 14, where the voltage and current are in phase with each other. The synchronised current is shown for phase A.

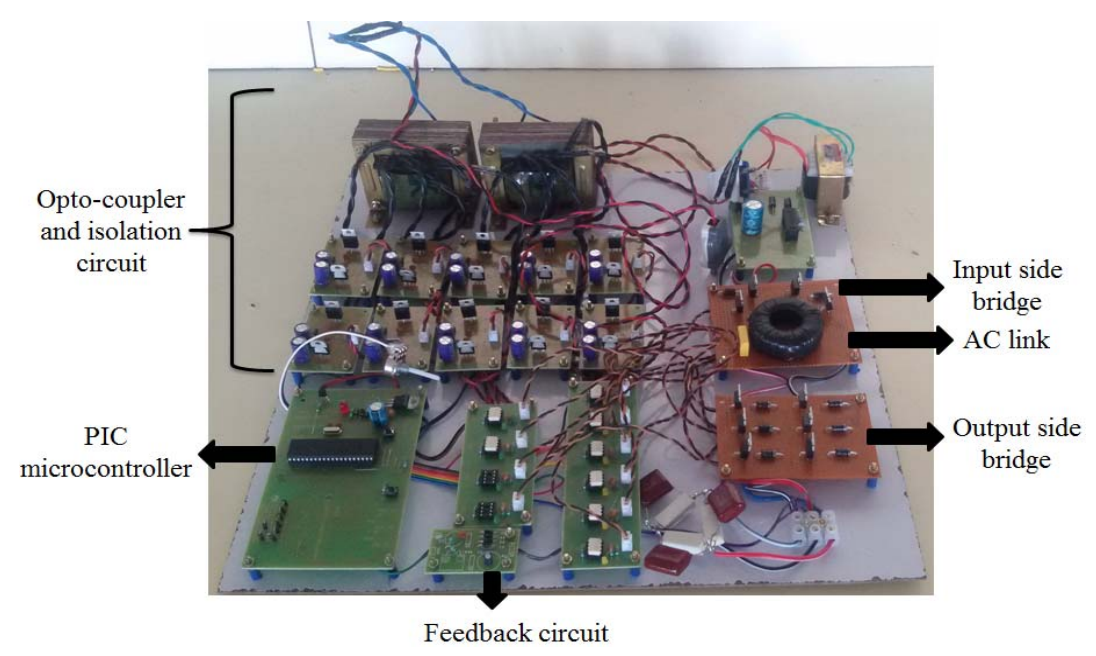

Figure 12. Hardware setup of the sparse AC-link inverter.

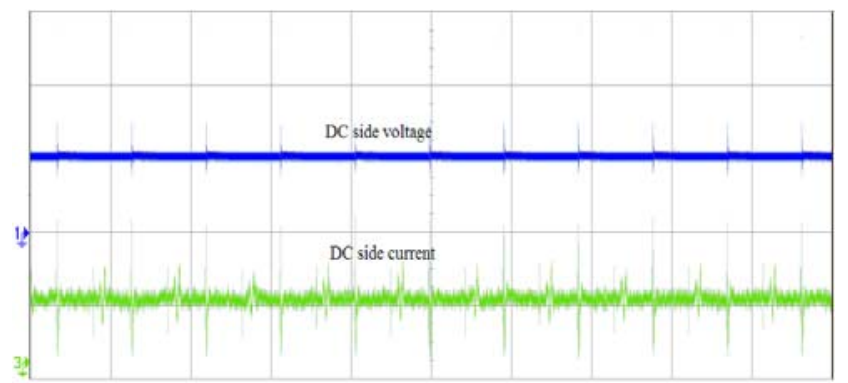

Figure 13. Direct current (DC) side voltage (200 V/division) and current (5 A/division).

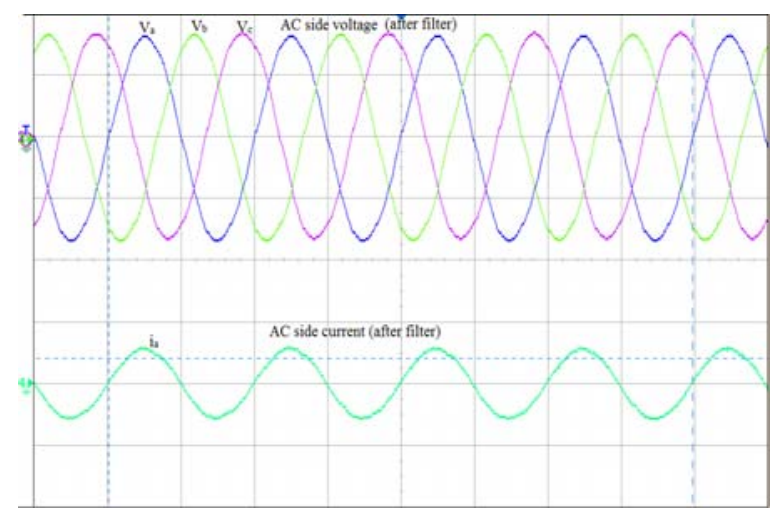

Figure 14. Alternating current (AC) side voltage ( $200 \mathrm{~V} /$ division) and current (5 A/division). 


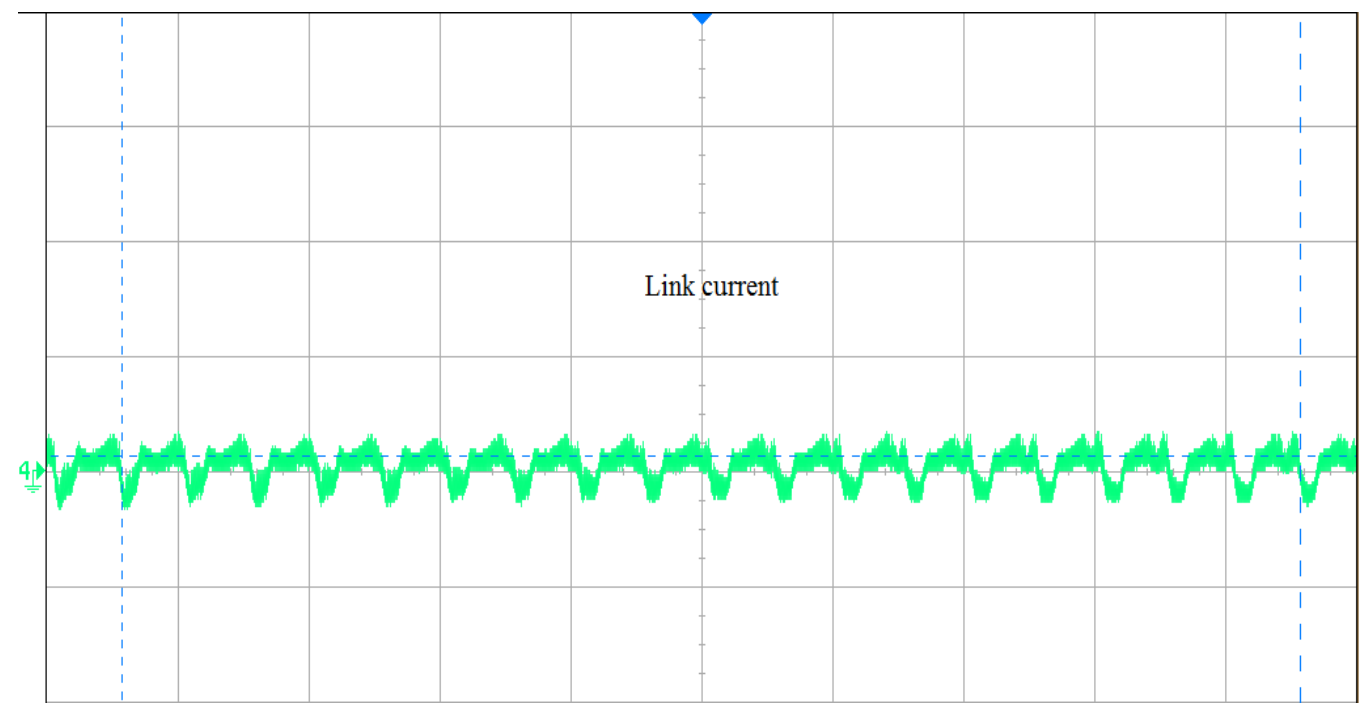

Figure 15. Link current (20 A/division).

The output AC link current was sinusoidal (Fig. 15). The output AC current obtained was approximately $5 \mathrm{~A}$.

From the results, it can be observed that a nearly sinusoidal voltage and current were obtained using a sparse AC-link inverter with reduced switches.

\section{Conclusion}

This paper presents a soft-switched AC-link sparse inverter with reduced switches. The proposed inverter has some advantages such as zero voltage upon turn $\mathrm{ON}$ and soft turn OFF of switches. Although the proposed inverter has reduced switches compared to the existing sparse inverter, the efficiency of the system is not affected. The inverter has an LC (InductorCapacitor) pair which acts as a partial resonant circuit. This inverter provides isolation between the input and output without a transformer. Therefore, the inverter is more reliable and compact for a grid-connected PV system. The performance of the inverter was evaluated through both simulated and experimental results.

\section{Acknowledgment}

The authors wish to thank the management of SSN College of Engineering, Chennai, India, for providing all the facilities to carry out this work.

\section{References}

Amirabadi M, Toliyat HA, Alexander W (2009), Battery-utility interface using soft switched AC link supporting low voltage ride through. IEEE Energy Conversion Congress Expo and Conference. San Jose, CA, USA. 2606-2613.

Amirabadi M (2013), Soft-switching highfrequency ac-link universal power converters with galvanic isolation. Ph.D. dissertation, Texas A\&M University, College Station, TX, USA.

Amirabadi M, Baek J, Toliyat HA (2014), Sparse ac-link buck-boost inverter. IEEE Transactions on Power Electronics 29(8): 39423953.

Amirabadi M, Balakrishnan A, Toliyat $\mathrm{H}$, Alexander W (2014), High frequency ac-link PV inverter. IEEE Transactions on Industrial Electronics 61(1): 281-291.

Amirabadi M, Toliyat HA, Alexander W (2009), Battery-utility interface using soft switched AC link buck boost converter. Electric Machines and Drives Conference 1299-1304.

Atcitty S, Granata JE, Quinta MA, Tasca CA (2011), Utility-scale grid-tied PV inverter reliability workshop summary report. Sandia National Labs, Sandia Rep. SAND2011-4778.

Balakrishnan A, Toliyat HA, Alexander WC (2008), Soft switched ac link buck boost converter. Twenty-Third Annual IEEE Appl. Power Electronics Conference Exp, Austin, Texas: IEEE 1334-1339. 
Carlson DE (1989), Fossil Fuels. The greenhouse effect and photovoltaics. IEEE Aerospace and Electronics Systems Magazine, 4(12): 3-7.

Chakraborty S, Kramer B, Kroposki B (2009), A review of power electronics interfaces for distributed energy systems towards achieving low-cost modular design. Renewable and Sustainable Energy Reviews 13(9): 2323-2335.

Kjaer SB, Pedersen JK, Blaabjerg F (2005), A review of single-phase grid-connected inverters for photovoltaic modules. IEEE Transactions on Industry Applications 41(5): 1292-1306.

Kerekes T, Teodorescu R, Rodriguez P, Vazquez G, Aldabas E (2011), A new high-efficiency single-phase transformerless PV inverter topology. IEEE Transactions on Industrial Electronics 58(1): 184-191.

Qin YC, Mohan N, West R, Bonn R (2002), Status and needs of power electronics for photovoltaic inverters. Sandia National Labs, Sandia Rep.: SAND2002-1535.

Shen WX (2008), Design of standalone photovoltaic system at minimum cost in
Malaysia. IEEE Conference on Industrial Electronics and Applications 702 -707.

Sood PK, Lipo TA, Hansen IG (1988), A versatile power converter for high frequency link systems. IEEE Transactions on Power Electronics 3(4): 383-390.

Subudhi B, Pradhan RA (2013), Comparative study on maximum power point tracking techniques for photovoltaic power systems. IEEE Transactions on Sustainable Energy 4(1): 89-98.

Toliyat H A, Balakrishnan A, Amirabadi M, Alexander W (2008), Soft switched ac-link $\mathrm{AC} / \mathrm{AC}$ and AC/DC buck-boost converter. In: IEEE Power Electronics Specialist Conference; 15-19 June 2008; Rhodes: IEEE: 4168-4176.

Villalva MG, Gazoli JR, Filho ER (2009), Comprehensive approach to modeling and simulation of photovoltaic arrays. IEEE Transactions on Power Electronics 24(5): 11981208.

Zahedi A (2002), Development of a numerical model for evaluating the performance of renewable generation systems. Proceedings of IEEE TENCON, 1950-1953. 